\title{
REVISTAMATĒRIA
}

\section{Efeito do Tratamento Térmico de Solubilização e Estabilização na microestrutura de uma Junta Soldada com Aço Inox 347}

\author{
Effect of Solubilization and Stabilization Heat \\ Treatment on Microstructure of a 347 \\ Stainless Steel Welded Joint
}

Renata Barbosa Gonçalves ${ }^{1}$, Luis Augusto Hernandez Terrones ${ }^{1}$, Ronaldo Paranhos da Rocha ${ }^{1}$

\footnotetext{
${ }^{1}$ Laboratório de Materiais Avançados - LAMAV, Centro de Ciência e Tecnologia, Universidade Estadual do Norte Fluminense Darcy Ribeiro, CCT/UENF, av. Alberto Lamego, 2000, 28015-620, Campos dos Goytacazes, RJ - Brasil. e-mail: renatahaa@gmail.com; lucho@uenf.br; paranhos@uenf.br
}

\section{RESUMO}

Neste trabalho faz-se o estudo da microestrutura formada na zona termicamente afetada (ZTA) e na zona fundida (ZF) de uma junta soldada pelo processo TIG automático no passe de raiz e soldagem a plasma nos passes de enchimento e acabamento em junta de topo com chanfro "V" simples, usando o aço inoxidável austenítico AISI 347. Além de estudar a condição como soldada, a peça após a soldagem foi submetida a tratamento térmico de solubilização a $1060^{\circ} \mathrm{C}$ e de estabilização a $900^{\circ} \mathrm{C}$. Os resultados mostram que, na condição como soldado houve crescimento de grão na ZTA, a formação de ferrita $\delta$ com diferentes morfologias e a precipitação de carbetos de $\mathrm{Nb}$ e $\mathrm{Cr}$. A ZF apresentou $13 \%$ de ferrita $\delta$. Após o tratamento térmico de solubilização, observou-se uma diminuição significativa do teor de ferrita $\delta$ na ZTA e na ZF, tendo sido observados carbetos de $\mathrm{Nb}$, distribuídos de forma mais dispersa e com tamanhos menores. Após o tratamento térmico de solubilização seguido de estabilização, foi observada uma diminuição ainda maior do tamanho dos carbetos de $\mathrm{Nb}$, mostrando a eficiência deste tratamento na dispersão destas partículas que contribuem para minimizar a possibilidade de ocorrer o fenômeno da sensitização. Os resultados permitem concluir que estes tratamentos térmicos são eficazes na solubilização da ferrita $\delta$, na formação de carbetos de $\mathrm{Nb}$ e para diminuir as alterações microestruturais resultantes do ciclo térmico da soldagem.

Palavras-chave: Aço inox 347, soldagem, solubilização, estabilização, microestrutura.

\section{ABSTRACT}

This paper makes the study of the microstructure formed in the heat affected zone (HAZ) and the melted zone (MZ) of a joint welded by automatic TIG process in the root bead and plasma in the filling and finish beads in a single $\mathrm{V}$ groove joint, using austenitic stainless steel AISI 347. In addition to study the as welded condition, the welded joint was submitted to thermal treatment of solubilization at $1060^{\circ} \mathrm{C}$ and stabilization at $900^{\circ} \mathrm{C}$. The results show that, in the as welded condition, there was grain grow in the HAZ, the formation of $\delta$ ferrite with different morphologies and the precipitation of $\mathrm{Nb}$ and $\mathrm{Cr}$ carbides. The $\mathrm{MZ}$ showed $13 \%$ of $\delta$ ferrite. After solubulization heat treatment, a significant reduction of $\delta$ ferrite content was observed in the $\mathrm{HAZ}$ and $\mathrm{MZ}$, with $\mathrm{Nb}$ carbides been observed, distributed in a more spread form and with smaller sizes. After solubilization followed by stabilization heat treatment, a greater reduction in the size of $\mathrm{Nb}$ carbides was observed, showing the efficiency of this heat treatment to spread these particles which contribute to minimize the possibility to occur the sensitization phenomena. The results allow to conclude that both heat treatments are effective to solubilization of $\delta$ ferrite, in the formation of $\mathrm{Nb}$ carbides and to reduce the microstructure changes resulting to the weld thermal cycles.

Keywords: Stainless steel 347, welding, solubilization, stabilization, microstructure. 


\section{INTRODUÇÃO}

Os aços inoxidáveis austeníticos são ligas do tipo $\mathrm{Fe}-\mathrm{Cr}-\mathrm{Ni}$, com o predomínio de uma microestrutura austenítica, onde o $\mathrm{Cr}$ é responsável por garantir a resistência à corrosão enquanto o Ni proporciona a extenção da região austenítica na temperatura ambiente [1,2]. Estes aços quando estabilizados com adições de elementos como $\mathrm{Nb}, \mathrm{V}$ e Ti, mostram-se mais resistentes à sensitização e a corrosão intergranular [3].

A corrosão intergranular ocorre devido ao fenômeno de sensitização, que consiste na diminuição da quantidade de $\mathrm{Cr}$ em regiões próximas aos contornos de grão devido à formação de carbetos de $\mathrm{Cr}$ do tipo $\mathrm{M}_{23} \mathrm{C}_{6}$. Estes se formam porque o carbono tem grande afinidade química com o cromo. As regiões empobrecidas em cromo tornam-se mais suscetíveis à corrosão [4]. Também pode ocorrer redução da ductilidade e tenacidade $[5,6]$ conforme a morfologia e a quantidade de precipitados na microestrutura.

No aço inox 347, estabilizado com $\mathrm{Nb}$, ocorre à formação preferencial de carbetos de $\mathrm{Nb}$, que tem maior afinidade química com o carbono do que o Cr. A soldagem destes aços altera a microestrutura, que será dependente da composição química do material, dos ciclos térmicos realizados, das temperaturas a que são submetidos, sendo esta fortemente influenciada pela taxa de resfriamento [7].

O tratamento térmico de solubilização, quando aplicado em juntas soldadas, pode eliminar a precipitação de fases indesejáveis para que sejam mantidas as propriedades do aço. Este tem o objetivo de dissolver grande parte dos precipitados formados durante o processo de solidificação e manter os elementos de liga em solução sólida na matriz austenítica $[8,9]$.

Submeter posteriormente o material solubilizado a tratamento de estabilização torna-se mais eficaz, pois os carbetos de $\mathrm{Nb}$ dissolvem-se em maior quantidade e no resfriamento se associam a maior quantidade de carbono. Este procedimento é o mais indicado para evitar a sensitização das peças soldadas e componentes fundidos durante serviço em alta temperatura [10].

Neste trabalho são estudadas as alterações na microestrutura das diferentes zonas de uma junta soldada do aço inoxidável austenítico AISI 347 estabilizado com nióbio, após os tratamentos térmicos de solubilização e estabilização.

\section{MATERIAIS E MÉTODOS}

Chapas do aço inoxidável austenítico 347 com $15 \mathrm{~mm}$ de espessura e chanfro em "V" foram soldadas pelo processo TIG automático no passe de raiz, seguido de dois cordões de solda por soldagem a plasma no passe de enchimento e acabamento. A Tabela 1 mostra a composição química do aço 347 e do metal de adição utilizado. Amostras da junta soldada foram submetidas a tratamento térmico de solubilização e em seguida a tratamento térmico de estabilização, conforme a Tabela 2.

Tabela 1: Composição química do aço e do metal de enchimento.

\begin{tabular}{c|c|c|c|c|c|c|c|c|c|c|c|c}
\hline AÇO & $\mathbf{C}$ & $\mathbf{S i}$ & $\mathbf{M n}$ & $\mathbf{P}$ & $\mathbf{S}$ & $\mathbf{C r}$ & $\mathbf{N i}$ & $\mathbf{M o}$ & $\mathbf{N}$ & $\mathbf{A l}$ & $\mathbf{N b}$ & Outros \\
\hline AISI 347 & 0,047 & 0,41 & 1,85 & 0,027 & 0,002 & 17,43 & 9,02 & 0,01 & - & 0,0036 & 0,483 & - \\
\hline $\begin{array}{c}\text { Metal de } \\
\text { Adição } \\
\text { ER347 }\end{array}$ & 0,047 & 0,48 & 1,85 & 0,015 & 0,010 & 20,00 & 10,10 & 0,50 & $<0,6$ & - & - & $\mathrm{Cu}:<0,2$ \\
\hline
\end{tabular}

Tabela 2: Parâmetros utilizados no tratamento térmico das amostras.

\begin{tabular}{c|c|c|c|c}
\hline $\begin{array}{c}\text { Tratamentos } \\
\text { Térmicos }\end{array}$ & $\begin{array}{c}\text { Taxa de } \\
\text { Aquecimento }\end{array}$ & $\begin{array}{c}\text { Tempo no } \\
\text { patamar }\end{array}$ & Resfriamento & Aço \\
\hline $\begin{array}{c}\text { Solubilização a } \\
1060^{\circ} \mathrm{C}\end{array}$ & $7 \% / \mathrm{min}$ & $1 \mathrm{~h}$ & em água & AISI 347 soldado \\
\hline Estabilização a $900^{\circ} \mathrm{C}$ & $7^{\circ} / \mathrm{min}$ & $45 \mathrm{~min}$ & ao ar & AISI 347 solubilizado \\
\hline
\end{tabular}

A preparação metalográfica foi feita por lixamento úmido, polimento e ataque com ácido oxálico $10 \%$ por 60 s e com ácido nítrico $40 \%$ por 15 s. Estes são ataques eletrolíticos, tendo sido usada uma tensão de 0,02 
V. A seção transversal da solda foi observada em três condições: a) como soldado; b) após tratamento térmico de solubilização e c) após solubilização seguida de estabilização.

O metal base (MB), a zona termicamente afetada (ZTA) e a zona fundida (ZF) foram observados por microscopia ótica (MO) e eletrônica de varredura (MEV), com análise por EDS em regiões selecionadas. A ferrita $\delta$ foi quantificada na ZF da amostra como soldada, pelo método da contagem de pontos, em micrografias com aumento de 400x, próxima ao primeiro passe, no centro e próxima ao último passe, em um total de 18 micrografias.

\section{RESULTADOS E DISCUSSÃO}

$\mathrm{Na}$ amostra como soldada, a microestrutura do MB, observada por microscopia ótica, é característica do aço inoxidável austenítico 347: consiste de grãos austeníticos de diferentes tamanhos e com a presença de alguns precipitados no interior e nos contornos dos grãos [5,6]. Na Figura 1(a) são destacados os contornos de grão (i), maclas (ii), e carbetos (iii). A Figura 1(b) permite a visualização da ferrita $\delta$ dispersa na microestrutura. A ZTA, Figura 1(c), apresenta na sua microestrutura um aumento no tamanho de alguns grãos e o aparecimento de novos grãos pequenos, consistindo de um mecanismo de crescimento anormal com recristalização secundária $[2,11]$. Na ZTA mais próxima à ZF, que atingiu altas temperaturas (ZTA-AT), observa-se maior teor de ferrita $\delta$ e uma diminuição desta na microestrutura da ZTA mais próxima do MB. Também destaca-se que a tendência da precipitação da ferrita $\delta$, nesta zona, foi ao longo dos contornos de grão como indicado pelas setas na Figura 1(d).

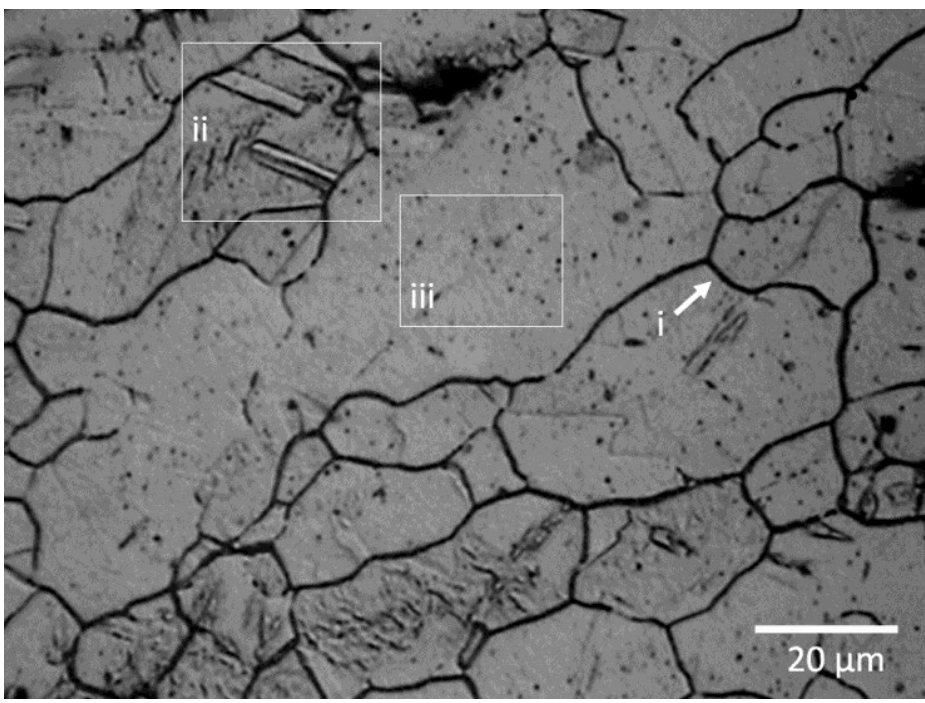

(a)

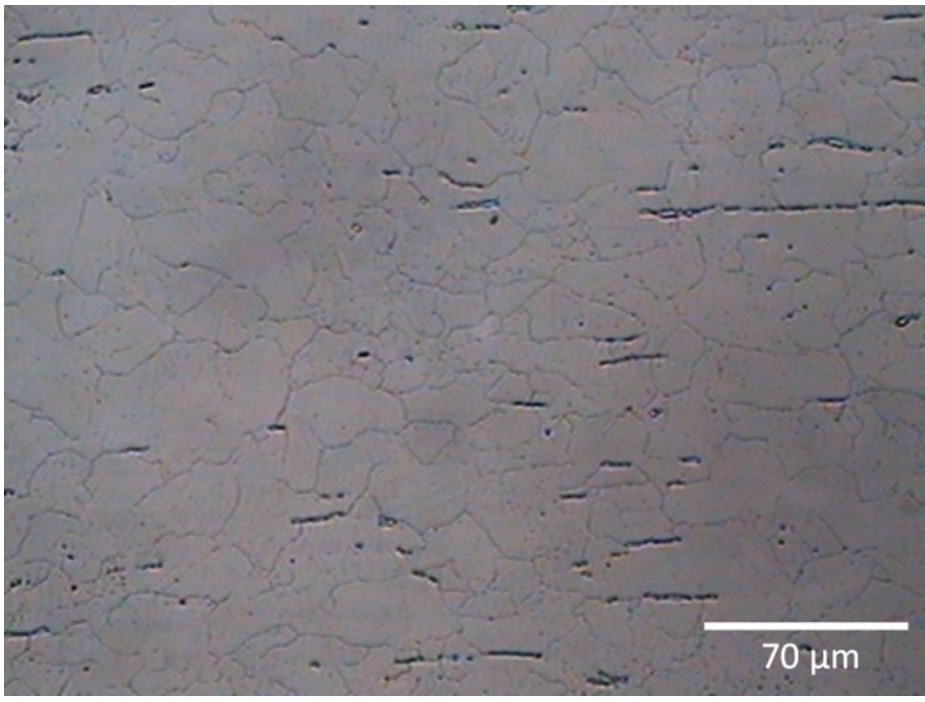

(b) 


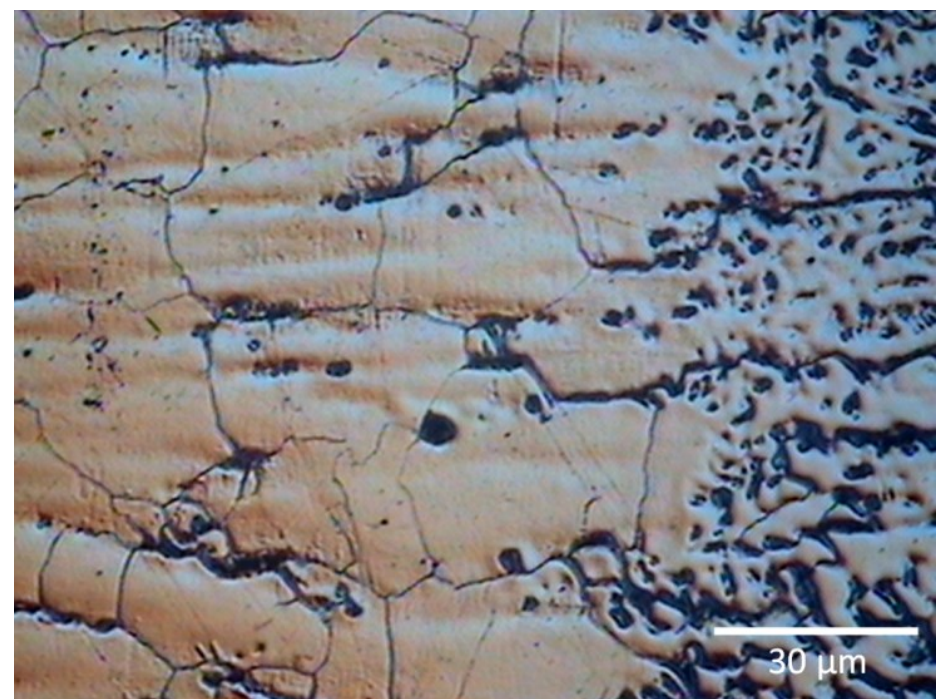

(c)

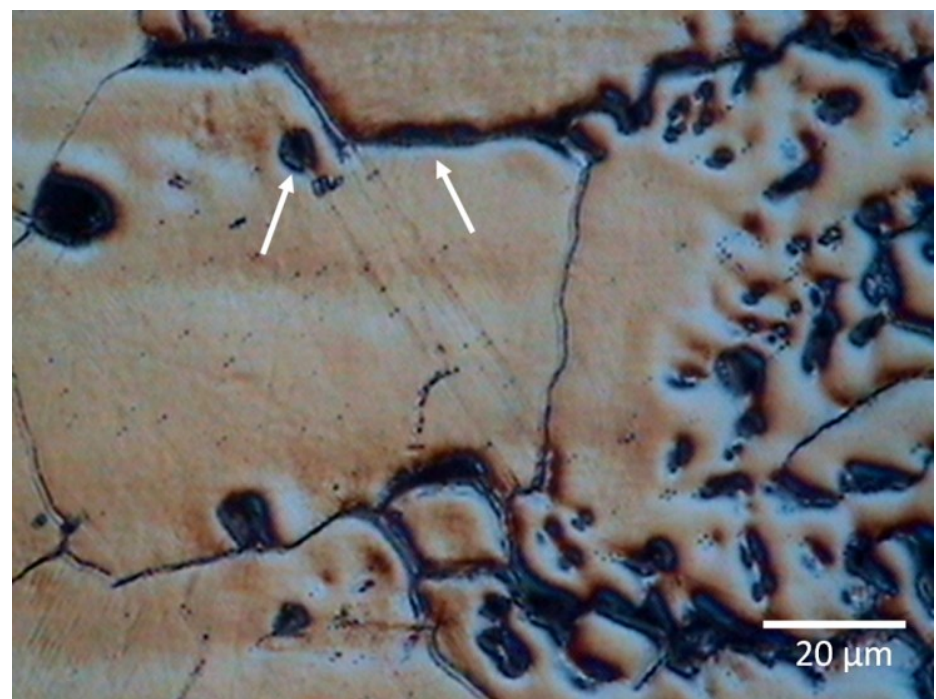

(d)

Figura 1: Microestrutura das diferentes regiões da amostra na condição soldada.

A figura 2(a) mostra precipitados com diferentes morfologias na ZTA. A análise por EDS identificou a presença de carbetos de $\mathrm{Nb}$ identificados com o número 1, com um intenso pico para o $\mathrm{Nb}$ (figura 2.b); de carbeto de $\mathrm{Cr}$ identificados com o número 2 (figura 2.c); e a ferrita delta, identificadas com o número 3 , com diferentes morfologias. Em geral os carbetos de $\mathrm{Nb}$ apresentam um tamanho menor do que o da ferrita $\delta$ e maior do que os carbetos de $\mathrm{Cr}$, com tendência a se precipitar na ferrita $\delta$ [12].

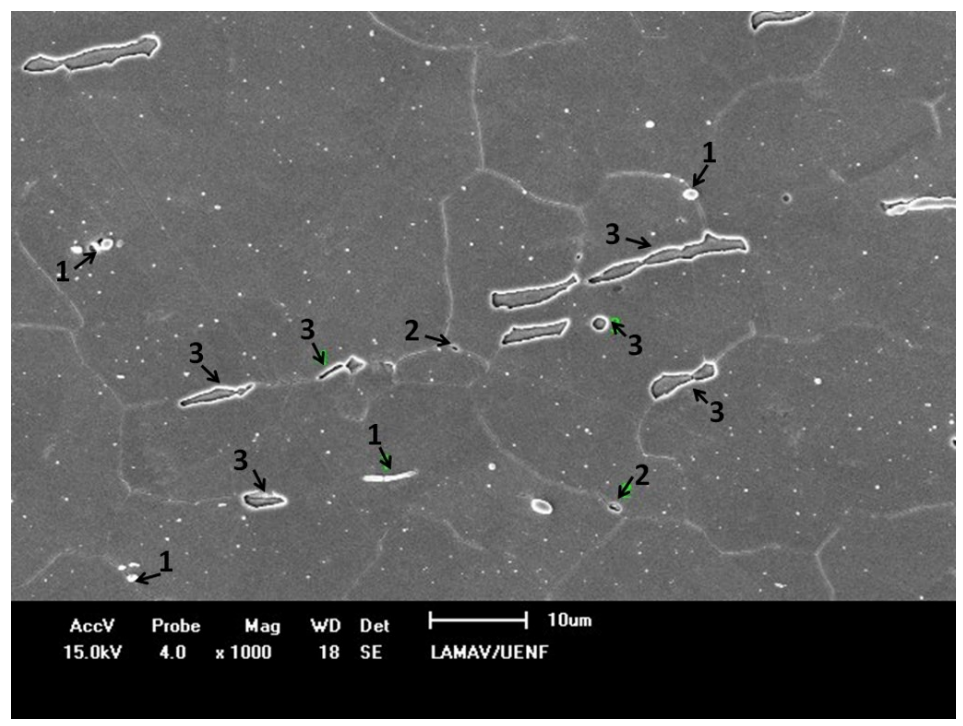


(a)

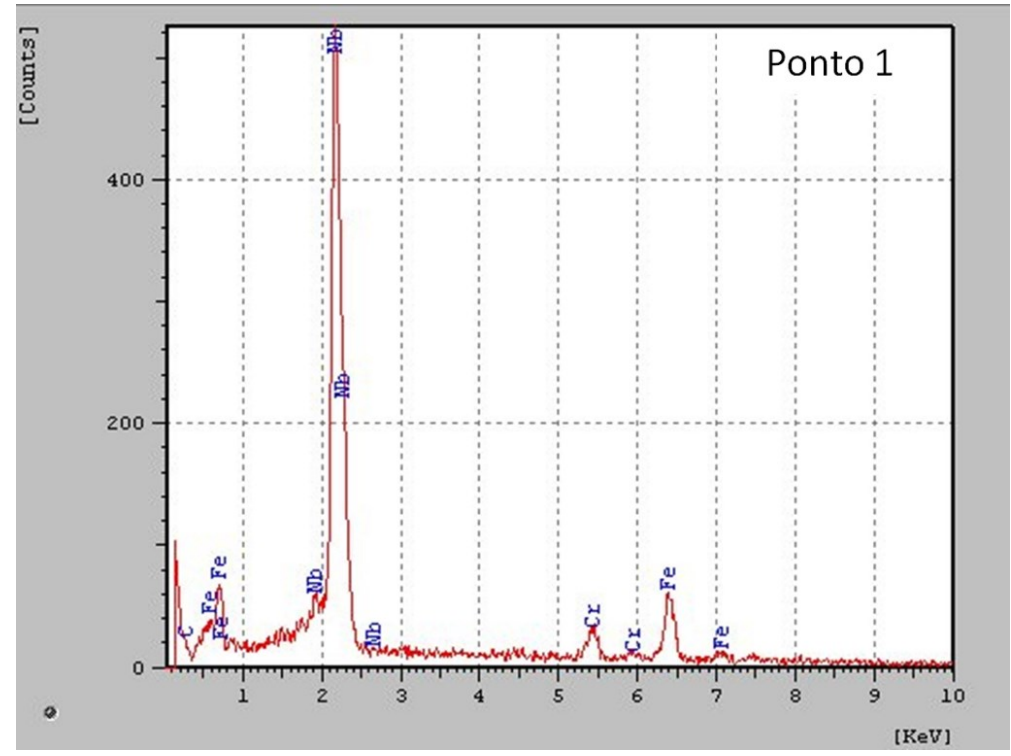

(b)

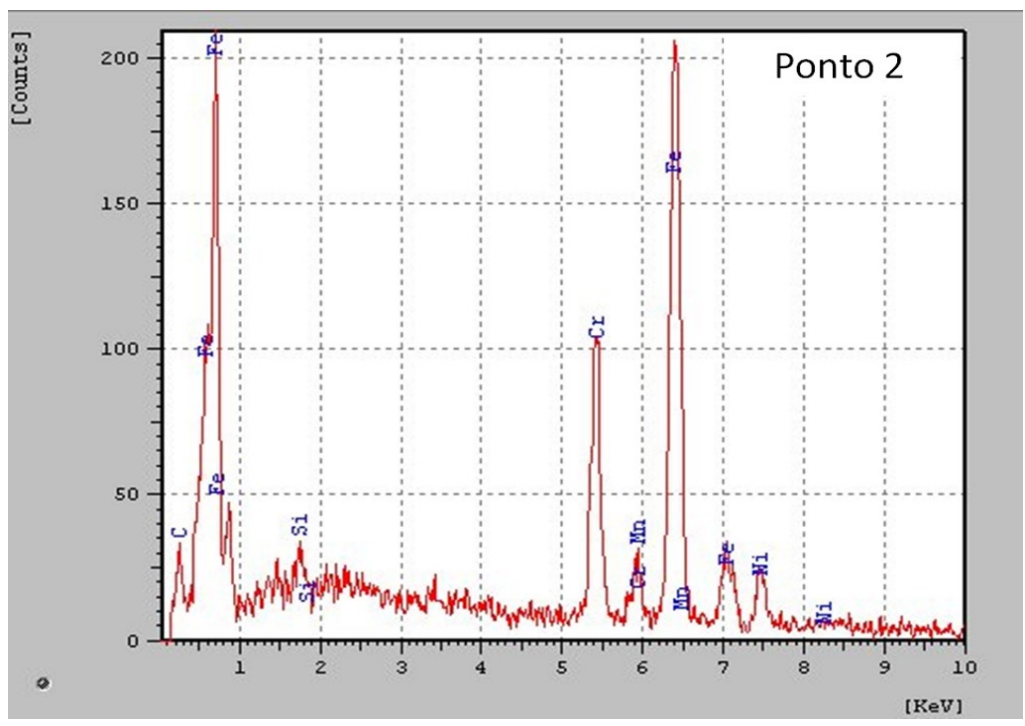

(c)

Figura 2: Análise por EDS de precipitados na ZTA, amostra na condição soldada.

Na ZF a análise por EDS permitiu identificar precipitados semelhantes aos encontrados na ZTA como carbeto de $\mathrm{Nb}$, ferrita delta e carbeto de cromo. A microestrutura consiste de uma matriz austenítica, com intensa precipitação de ferrita $\delta$ principalmente com morfologia vermicular e laminar, Figura 3(a). Numa solidificação primariamente austenítica, a ferrita $\delta$ se solidifica nas regiões entre os braços das dendritas, com morfologia característica vermicular [13]. Esta tende a se apresentar de forma mais espaçada enquanto que a ferrita laminar apresenta-se com um formato mais regular, consistindo de placas paralelas (numerosas ripas).

A ZF mais próxima da ZTA, Figura 3(b), apresenta uma diferença maior em sua microestrutura, pois a ferrita $\delta$ apresenta-se com um maior espaço entre si, sendo identificadas como pequenas partículas esféricas e alongadas, Figura 3 (c). Comparando-se a microestrutura da ZF próxima a ZTA, Figura 3 (b) com a do centro da ZF, Figura 3 (d) e (e), percebe-se que, no centro ocorre maior precipitação da ferrita $\delta$ nos contornos de grão.

A análise quantitativa da microestrutura da $\mathrm{ZF}$ apresentou um teor de $13 \%$ de ferrita $\delta$, valor bem superior ao presente no MB. A influência da quantidade de ferrita $\delta$ na microestrutura dos aços está relacionada com a resistência à corrosão e as propriedades mecânicas. Na ZF, devido aos ciclos térmicos da soldagem, 
uma alta fração de ferrita $\delta$ é encontrada, sendo considerada prejudicial. No entanto, cerca de $5 \%$ de ferrita $\delta$ retida na microestrutura evita a ocorrência de trincas na solidificação em operações de soldagem [14,15]. Portanto pequenos teores de ferrita $\delta$ favorecem a precipitação de carbetos no seu interior, ao invés de se precipitarem nos contornos de grão austenítico, o que reduz a susceptibilidade à sensitização [16,17].

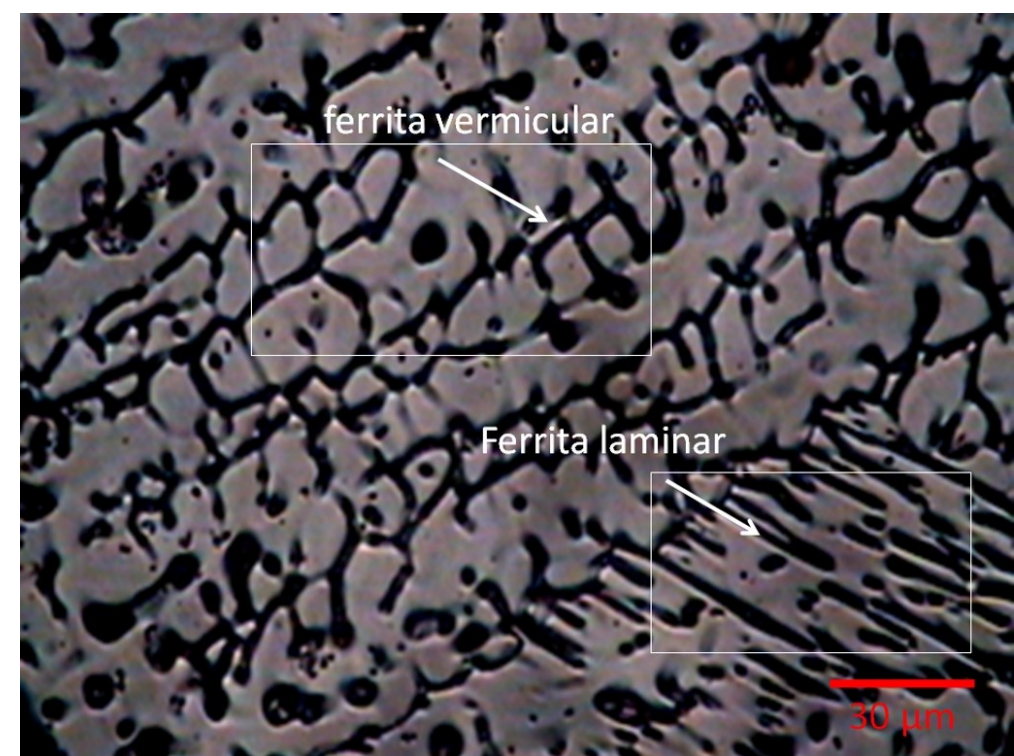

(a)

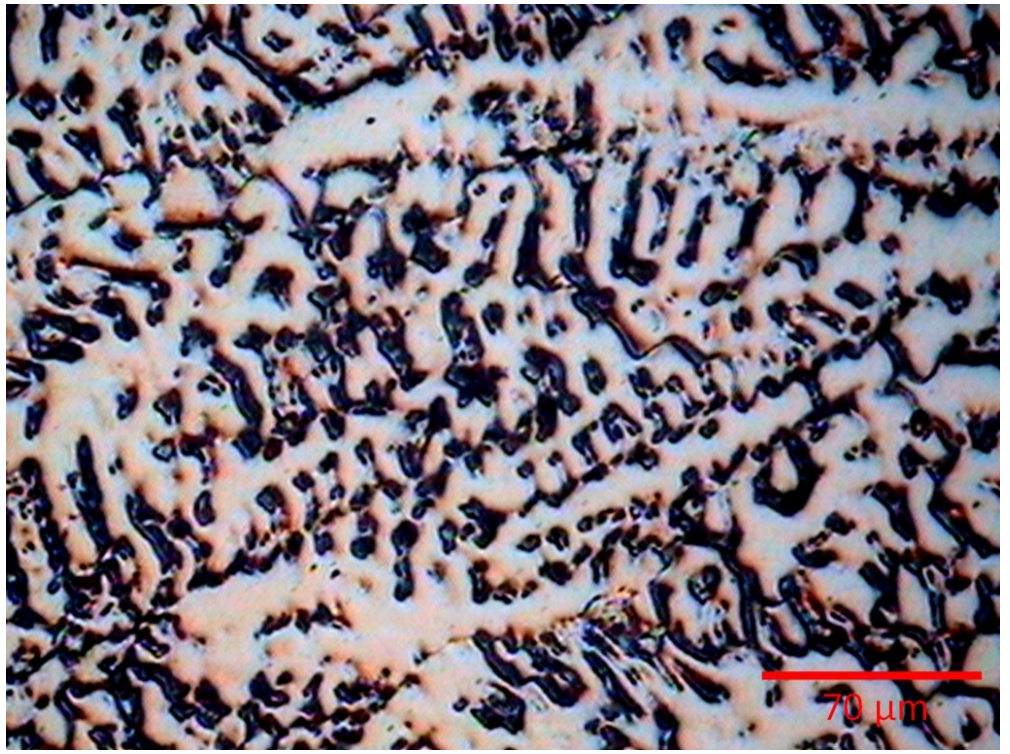

(b)

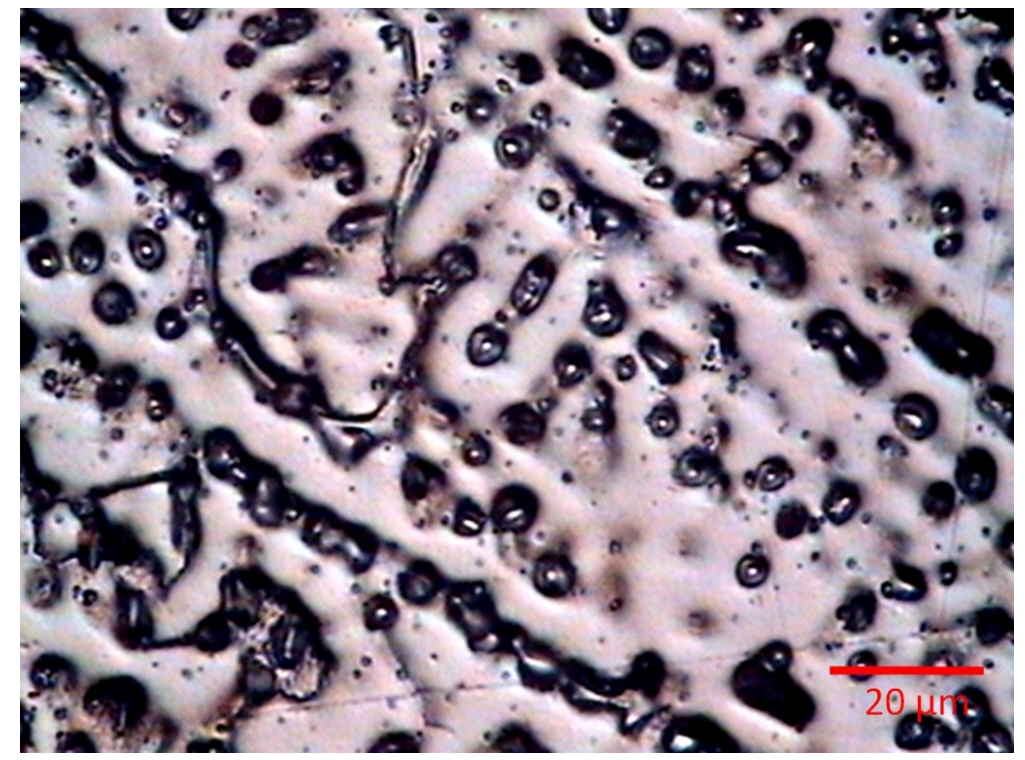




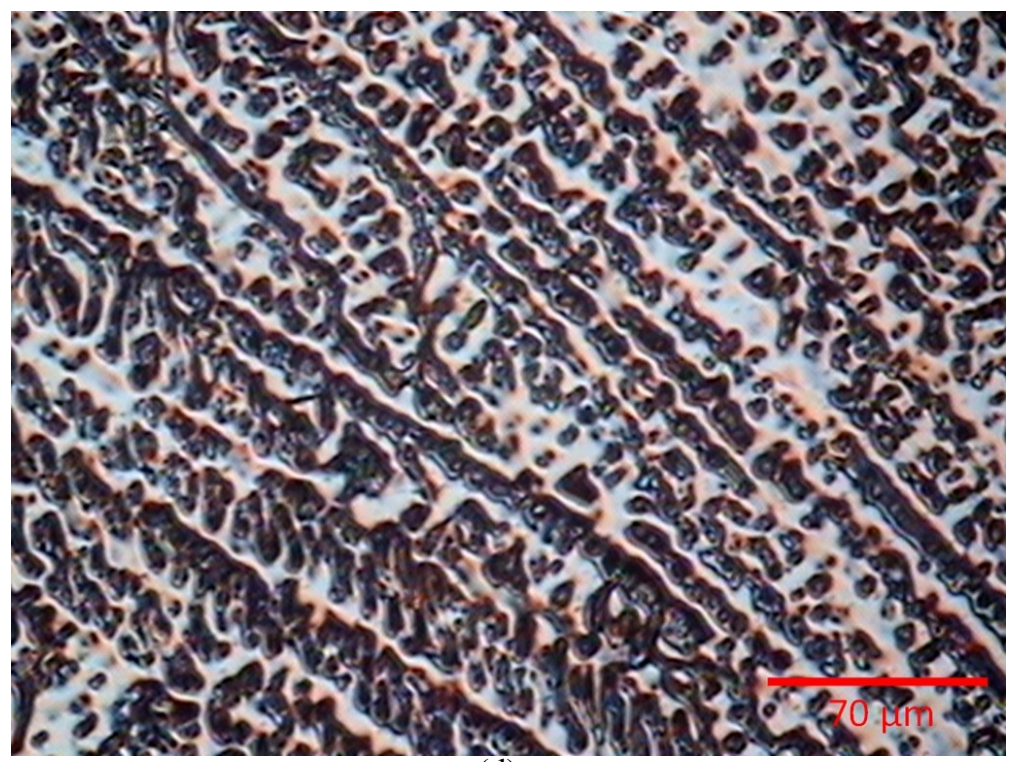

(d)

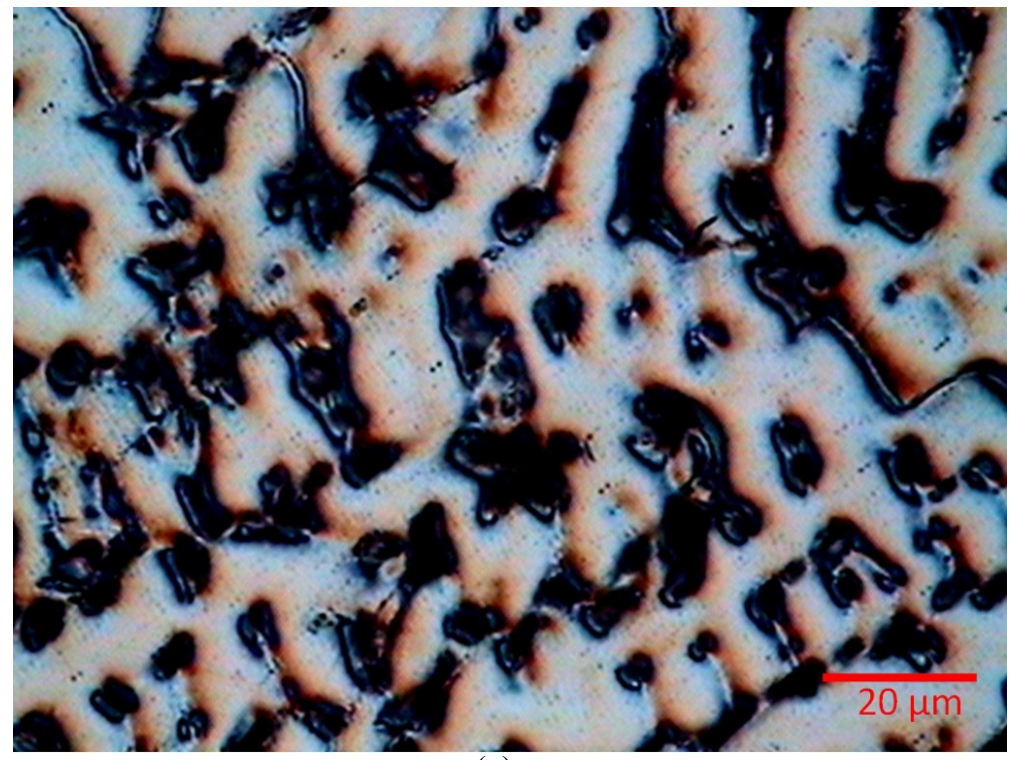

(e)

Figura 3: ZF na condição como soldado: precipitação da ferrita $\delta$ com morfologia vermicular e laminar (a); ZF mais próxima da ZTA (b) e (c); centro da ZF (d) e (e).

A recomendação para realização de tratamento térmico de solubilização pós soldagem tem como objetivo dissolver parte da ferrita $\delta$ e promover a redistribuição do $\mathrm{Nb}$, elemento que deve se combinar com o carbono da liga e, assim, evitar a precipitação de carbetos de $\mathrm{Cr}$. A adição de $\mathrm{Nb}$ é feita para provocar a precipitação de carbetos finos do tipo $\mathrm{NbC}$, que evitam a sensitização do material [10]. Desta forma, os aços inoxidáveis austeníticos estabilizados ao $\mathrm{Nb}$, como o 347, podem ser utilizados em serviço em elevadas temperaturas $\left(500-800^{\circ} \mathrm{C}\right)$, devido à boa resistência à fluência da estrutura austenítica [2].

A microestrutura do $\mathrm{MB}$ do aço solubilizado a $1060^{\circ} \mathrm{C}$ por $1 \mathrm{~h}$ e resfriado em água é semelhante à condição como recebido, Figura 1 (a) e (b), pois o MB não sofreu influência do ciclo térmico da soldagem e do tratamento térmico.

Na ZTA identificou-se, numa análise qualitativa, que após o tratamento térmico de solubilização os carbetos de $\mathrm{Nb}$ na microestrutura se precipitaram com tamanhos menores. O tempo e a temperatura utilizados foram suficientes para diminuir o tamanho e favorecer a dispersão dos carbetos de $\mathrm{Nb}$ na matriz como pode ser observado comparando-se a microestrutura mostrada na Figura 4 com a da ZTA como soldada, Figura 2.a. A análise EDS mostra que no ponto 1 está a ferrita $\delta$ (Figura 4.b), no ponto 2 o carbeto de Nb (Figura 4.c) e no ponto 3 a matriz austenítica(Figura 4.d). Também foi observada a precipitação de carbeto de Nb sobre a 
ferrita $\delta$. Não foi observada a presença de carbeto de Cr.

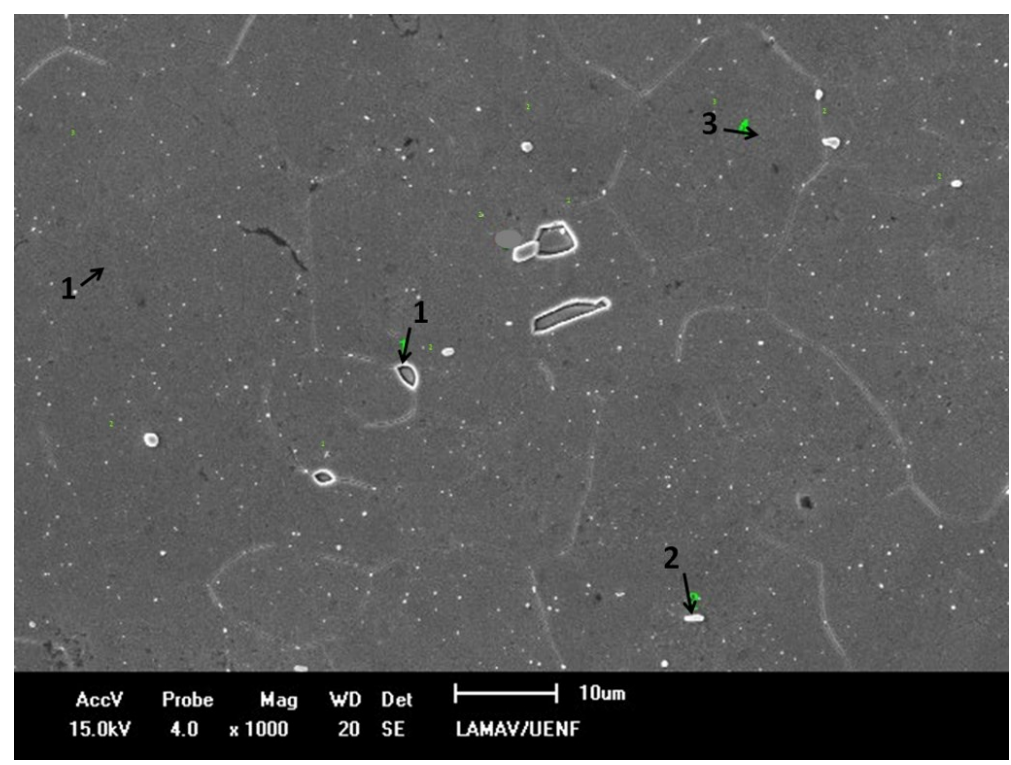

(a)

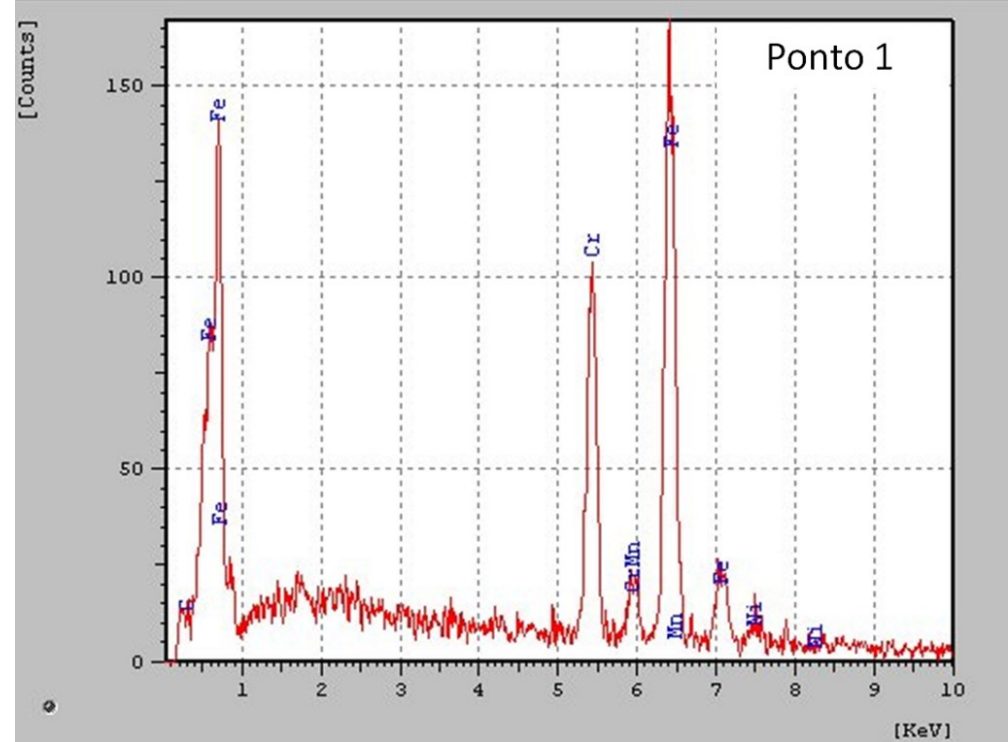

(b)

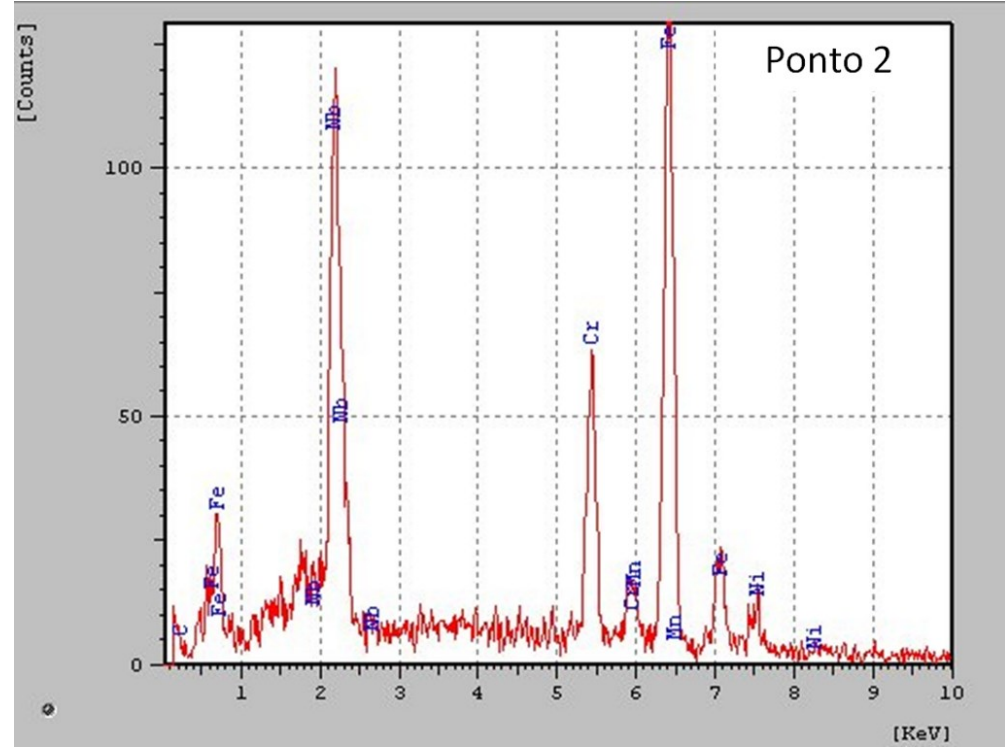




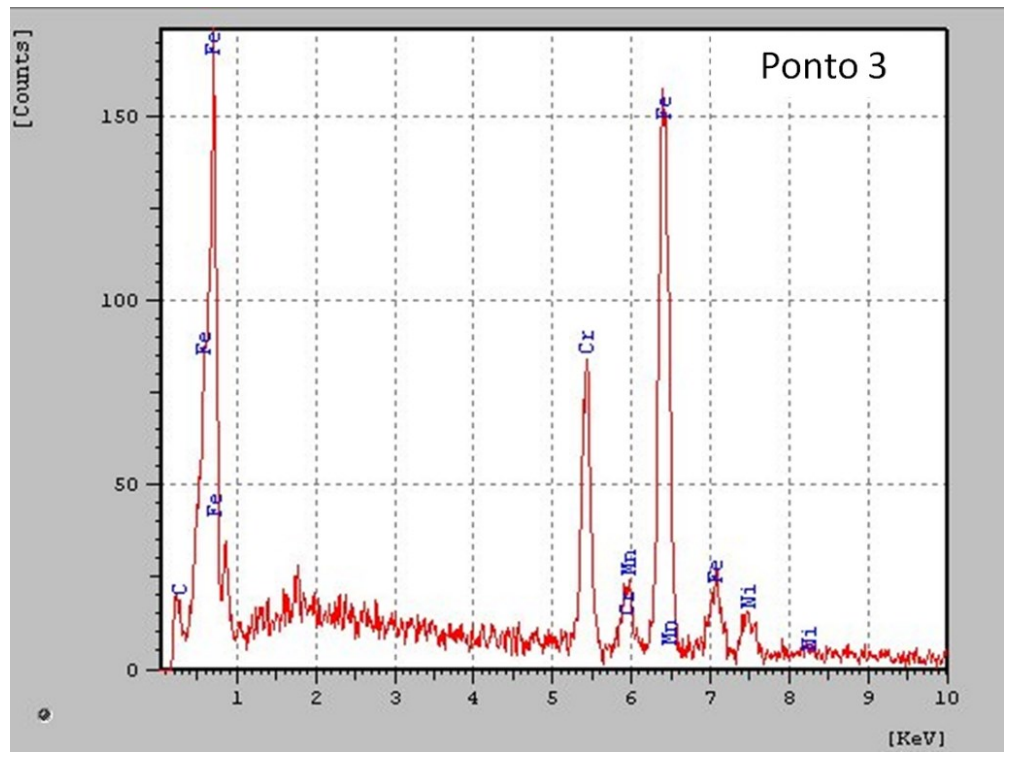

(d)

Figura 4: Análise qualitativa por EDS dos precipitados indicados na ZTA do aço 347 após solubilização.

$\mathrm{Na}$ ZF a análise por EDS de precipitados teve os picos com a intensidade dos elementos muito parecidos com os obtidos para os precipitados presentes na ZTA, por isso não são mostrados. Nesta zona a microestrutura, Figura 5, tem a delimitação dos contornos de grãos da austenita mais evidentes e a precipitação da ferrita $\delta$ no seu interior e nos contornos. A ferrita $\delta$ encontrada possui morfologia esférica e/ou menos alongada e sua quantidade foi bastante reduzida, quando comparada com a condição como soldado (Figura 3). A solubilização da ZF promoveu uma significante modificação da microestrutura em relação à condição como soldada, tornando-a mais semelhante à do MB.

Segundo a análise quantitativa realizada por Pessanha nesta mesma junta soldada na condição de solubilizada, a porcentagem de ferrita $\delta$ na ZTA e ZF foi de aproximadamente 5\% [18]. Uma redução considerável, quando comparado com o teor de $13 \%$ de ferrita $\delta$ na microestrutura da ZF na condição como soldado.

De uma forma geral, foi observado que o tratamento térmico de solubilização promoveu uma redução da quantidade de ferrita $\delta$ na ZTA e ZF da junta na condição como soldada. Também ocorreu uma redistribuição dos carbetos de $\mathrm{Nb}$, o que é desejável, pois além de reduzir a possibilidade do carbono se ligar ao cromo diminui os locais para precipitação de possíveis carbetos, que deixariam o material susceptível a corrosão intergranular. A precipitação de carbetos de $\mathrm{Cr}$ foi evitada.

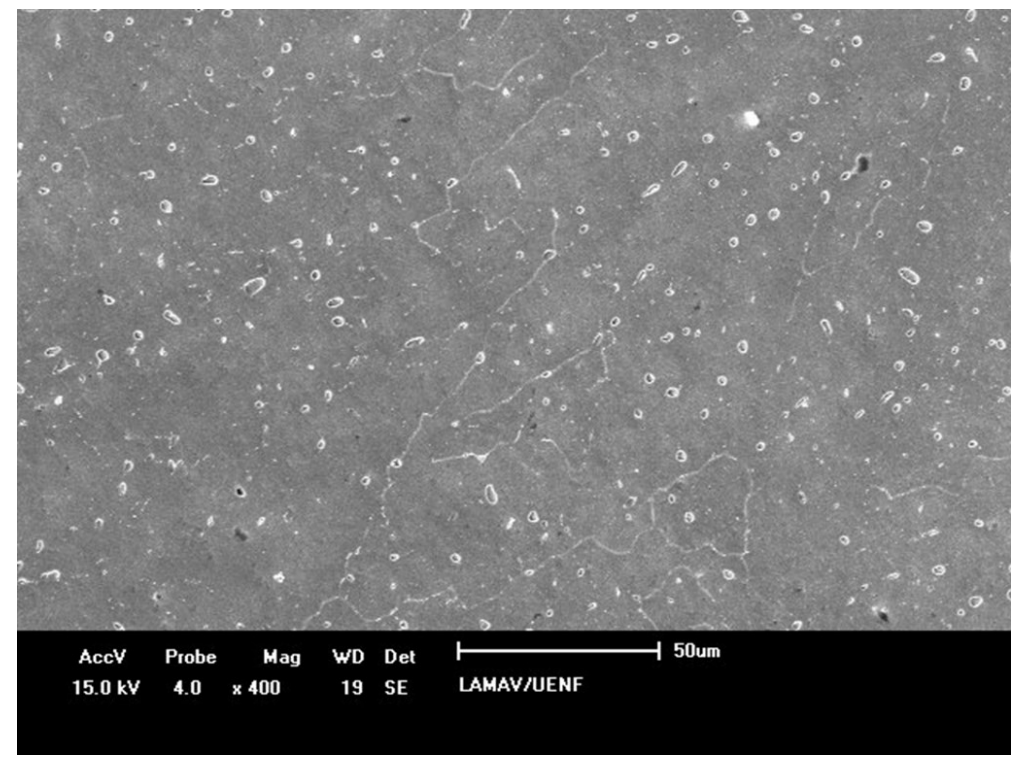

(a) 


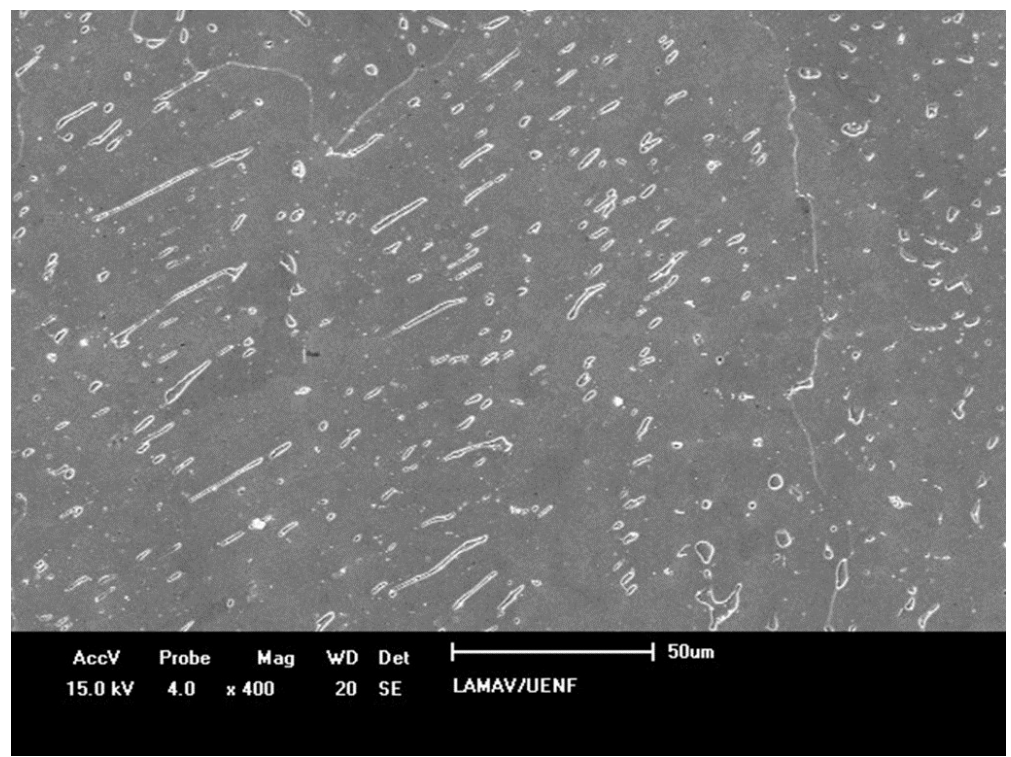

(b)

Figura 5: Microestrutura da ZF do aço 347 com tratamento térmico de solubilização a $1060^{\circ} \mathrm{C}$.

Nas amostras com tratamento térmico de solubilização seguido de estabilização, verificou-se que não ocorreram alterações significativas na microestrutura das diferentes zonas se comparadas com as encontradas nas amostras solubilizadas (Figuras 4 e 5), e se distinguem das encontradas no material na condição como soldado (Figuras 1 e 3 ).

A Figura 6 mostra a microestrutura da ZTA e a ZF da junta soldada após tratamento de solubilização seguido de estabilização. Destaca-se a presença de pequenas partículas de carbetos e a evidência dos contornos de grão da austenita na ZF. As características destas já são mais parecidas com as observadas no MB, tendo em vista que a ferrita $\delta$ foi diminuída significativamente se comparada com a mostrada na Figura 3, relativa à condição como soldada.

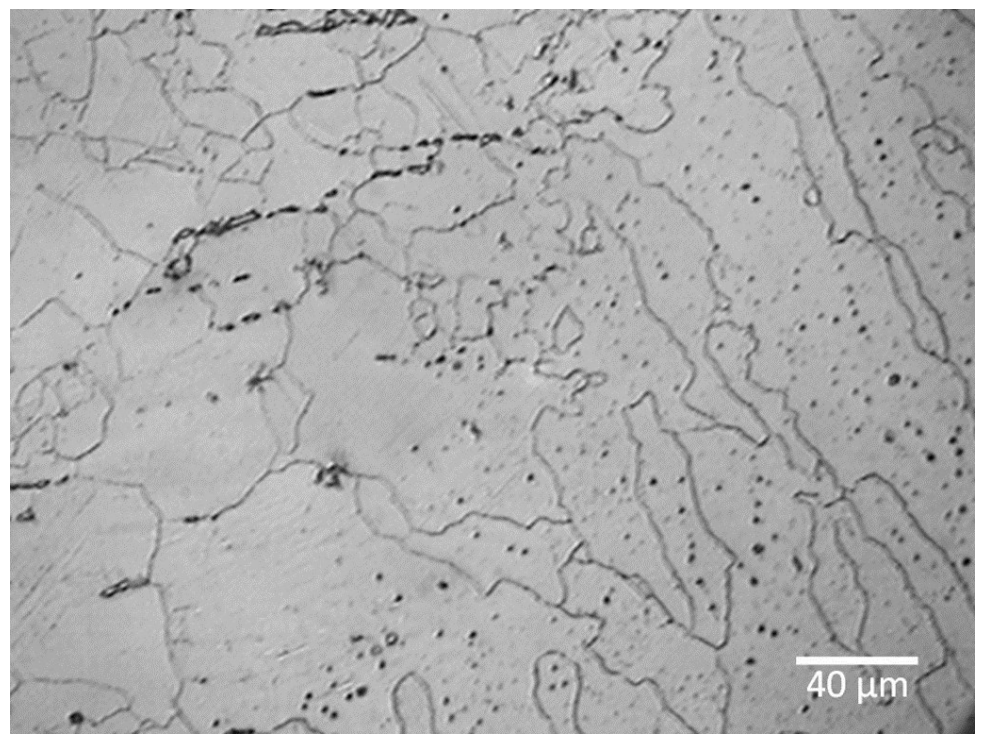

(a) 


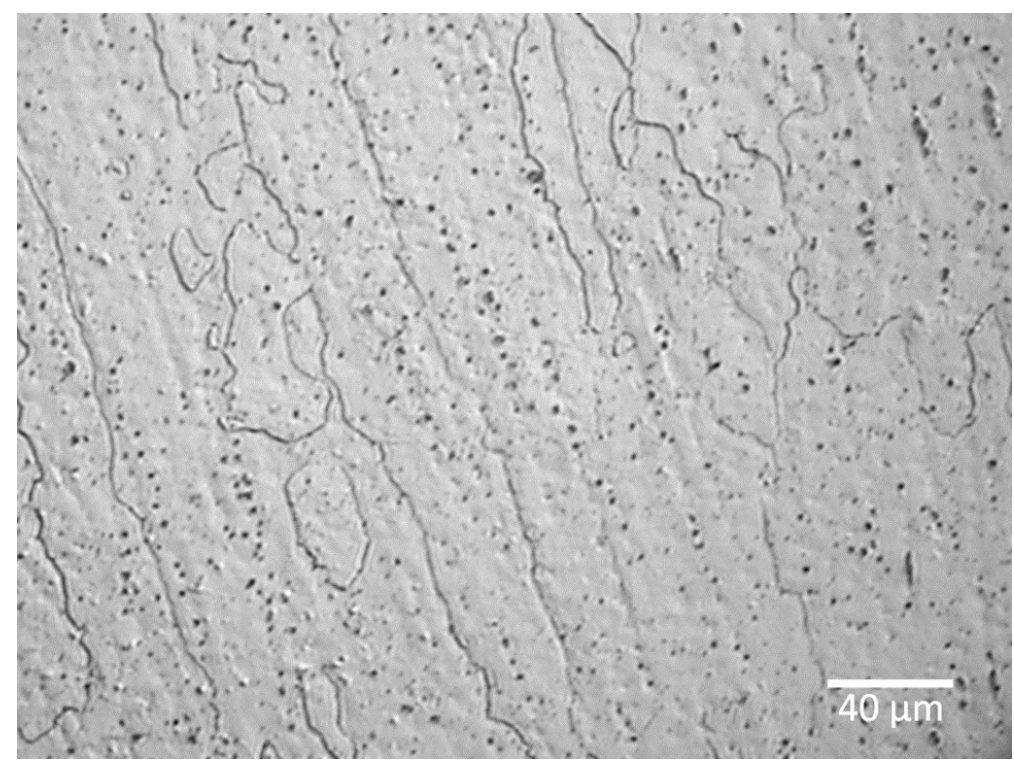

(b)

Figura 6: Microestrutura das zonas ZTA (a) e ZF (b), do aço inoxidável 347 com tratamento térmico de solubilização seguido de estabilização.

A precipitação dos diversos tipos de carbetos pode ocorrer em diferentes temperaturas [3,6,8,10,19] nos aços solubilizados expostos a temperaturas de serviço na faixa de $500^{\circ} \mathrm{C}$ a $800^{\circ} \mathrm{C}$, primeiramente ocorre a formação de $\mathrm{Cr}_{23} \mathrm{C}_{6}$, e não do carbeto $\mathrm{NbC}$. Recomenda-se que esses aços sejam submetidos a tratamento térmico de estabilização em temperaturas próximas ao nariz da curva de formação de carbetos de $\mathrm{Nb}$, isto é, em temperaturas próximas a $900^{\circ} \mathrm{C}$.

Este tratamento é fundamental para que o aço possa ser utilizado em aplicações na faixa de sensitização $\left(450^{\circ} \mathrm{C}-800^{\circ} \mathrm{C}\right)$, pois como a estabilização nessa temperatura provoca a precipitação dos carbetos $\mathrm{NbC}$, todo o carbono tende a ser retirado da solução sólida. Quando se compara aços estabilizados sem tratamento de solubilização com aços estabilizados após solubilização, o grau de sensitização neste último é significativamente menor [10].

Os precipitados encontrados na ZTA e ZF após tratamento térmico de solubilização seguido de estabilização, analisados de forma qualitativa, apresentam-se em maior quantidade, com um tamanho menor e distribuídos de forma mais uniforme na matriz. Nas análises por EDS mostradas na Figura 7, referentes à ZTA, foram identificados apenas precipitados de carbeto de $\mathrm{Nb}$, similares aos encontrados nas amostras com o tratamento térmico de solubilização. A ZF, apesar de não mostrada, também apresentou o mesmo comportamento.

Os resultados obtidos neste trabalho permitem concluir que, quando possível, o tratamento térmico de solubilização seguido de estabilização é uma ferramenta efetiva para o controle da microestrutura da junta soldada em aços inox tipo 347. Tanto na ZTA como na ZF ocorre redução significativa da ferrita $\delta$, e favorece a precipitação de carbetos de $\mathrm{Nb}$. Os carbetos de $\mathrm{Nb}$ são benéficos para as propriedades do material evitando o empobrecimento em $\mathrm{Cr}$ das regiões adjacentes aos contornos de grão e consequentemente melhorando a resistência a corrosão intergranular. Este é o caso de peças fabricadas em caldeirarias, como é o caso de tubos, onde podem, após a soldagem, ser alocadas em grandes fornos para a realização do tratamento térmico. 


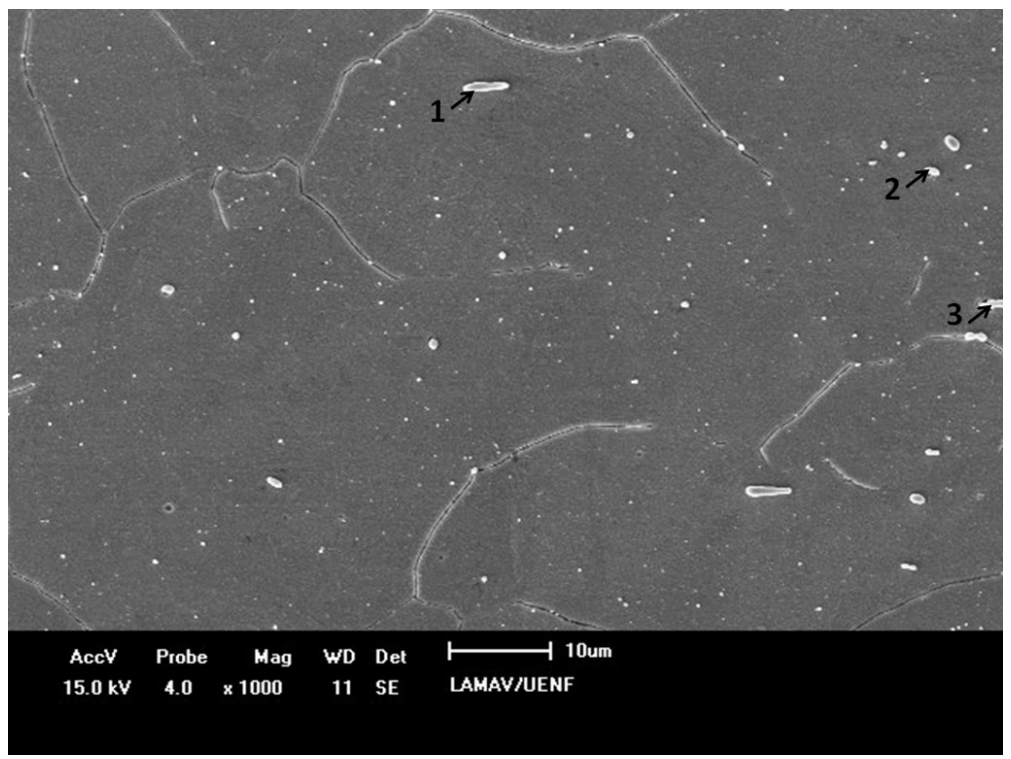

(a)

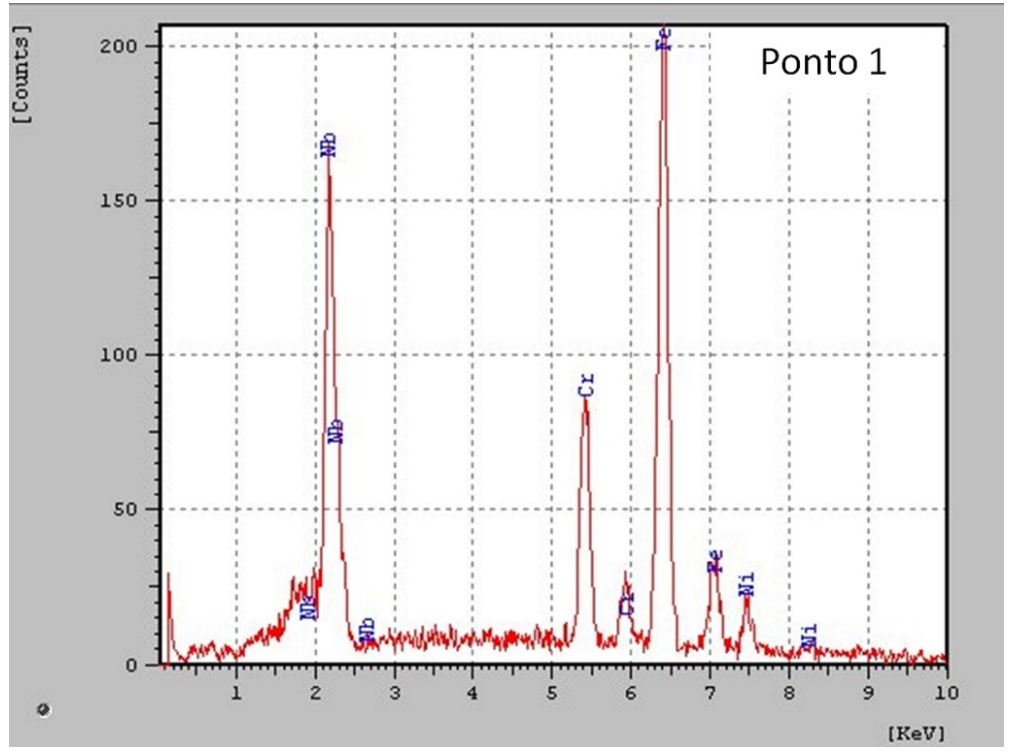

(b)

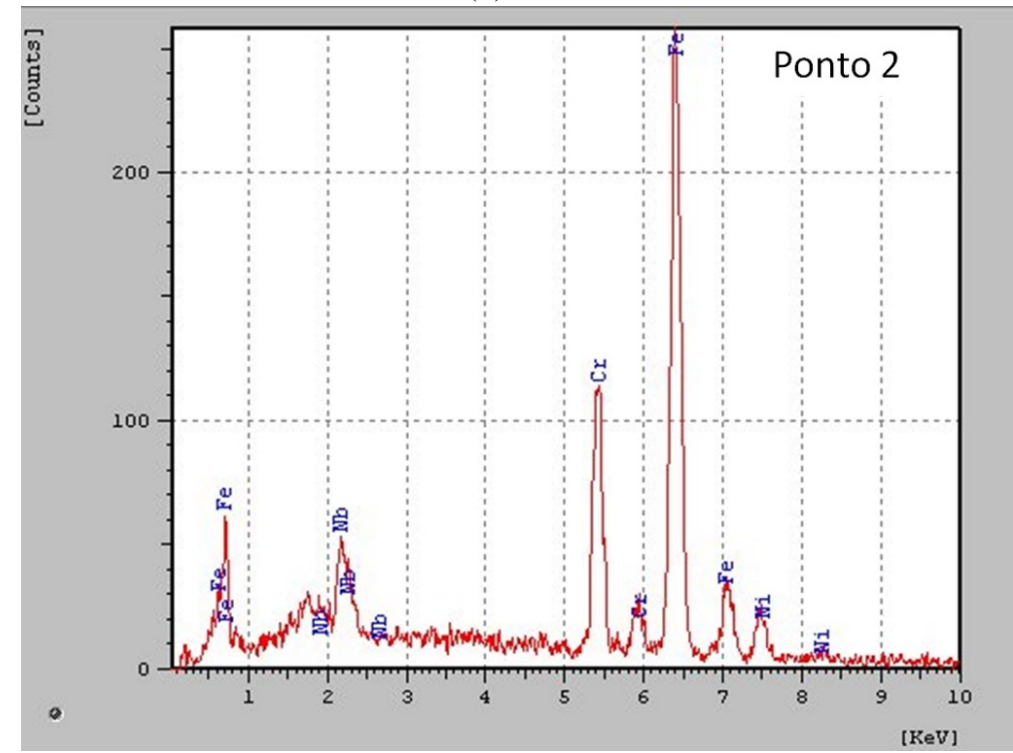

(c) 
Figura 7: Análise EDS de precipitados na ZTA do aço inoxidável 347 com tratamento térmico de solubilização seguido de estabilização: carbetos de $\mathrm{Nb}$ : (a) ponto 1; (b) ponto 2; (c) ponto 3.

\section{CONCLUSÕES}

Da análise do efeito dos tratamentos térmicos de solubilização e estabilização na microestrutura de uma junta soldada com aço AISI 347, pode-se concluir que:

- Na condição como soldado, a microestrutura da ZTA apresentou crescimento de grão austenitico com ferrita $\delta$ ao longo dos contornos dos grãos. A ZF apresentou cerca de $13 \%$ de ferrita $\delta$ com morfologia vermicular e laminar. Carbetos de $\mathrm{Nb}$ e $\mathrm{Cr}$ foram identificados.

- Após tratamento térmico de solubilização, observou-se na ZTA e na ZF uma diminuição da ferrita $\delta$ precipitada principalmente ao longo dos contornos de grão, porém com uma morfologia mais esférica e menos alongada do que na condição como soldado. Em relação aos carbetos, apenas os de Nb foram observados.

- Após tratamento térmico de solubilização seguido de estabilização, a ZTA e ZF apresentaram semelhança às observadas após tratamento de solubilização, porém com mais e menores carbetos de $\mathrm{Nb}$ dispersos na microestrutura.

- O tratamento térmico de solubilização seguido de estabilização é uma ferramenta efetiva para o controle da microestrutura da junta soldada, com provável melhoria na resistência à corrosão intergranular, evitando a sensitização.

\section{AGRADECIMENTOS}

Os autores agradecem a FAPERJ e ao LAMAV-CCT-UENF pelo apoio a esta pesquisa.

\section{BIBLIOGRAFIA}

[1] DOLINŠEK, S. "Work-hardening in the drilling of austenitic stainless steels", Journal of Materials Processing Technology. v. 133, p. 63-70, 2003.

[2] LUO, H.W., DONG, H., CHEN, L.F. "Grain Growth in Nb-Alloyed Stainless Steel of AISI 347 during Heating”, Materials Science Forum. v. 753, p. 345-348, 2013.

[3] LO, K.H., SHEK, C.H., LAI, J.K.L. "Recent Developments in Stainless Steels", Materials Science and Engineering R. v. 65, p. 39-104, 2009.

[4] TERADA, M., MITIKO, S., COSTA, I., PADILHA, A.F. "Microstructure and intergranular corrosion of the austenitic stainless steel 1.4970", Journal of Nuclear Materials. v. 358, p. 40-46, 2006.

[5] SASIKALA, G., MATHEW, M.D., RAO, B.S., et al. "Creep deformation and fracture behaviour of a nitrogen-bearing type 316 stainless steel weld metal”, Journal of Nuclear Materials. v. 273, pp. 257-264, 1999.

[6] TAVARES S.S.M., SOUZA V.M., SOUZA J.A., et al. "Influência dos tratamentos térmicos de estabilização e solubilização na resistência à corrosão intergranular do aço inoxidável AISI 347 fundido", Tecnologia em Metalurgia e Materiais. v. 4, n. 3, pp. 18-22, 2008.

[7] KARCI, F., KARÇAR, R., GUNDUZ, S. "The effect of process parameter on the properties of spot welded cold deformed AISI 304 grade austenitic stainless steel”, Journal of Materials Processing Technology. v. 209, pp. 4011-4019, 2009.

[8] MOURA, V., KINA, A.Y., TAVARES, S.S.M., et al. "Influence of stabilization heat treatments on microstructure, hardness and intergranular corrosion resistance of the AISI 321 stainless steel", Journal of Materials Science. v. 43, p. 536-540, 2008.

[9] RITONNI, M., MEI, P.R., MARTINS, M. "Efeito do tratamento térmico de solubilização na microestrutura e nas propriedades de impacto do aço inoxidável superaustenítico ASTM A 744 Gr. CN3MN", Revista Escola de Minas, v. 63, pp. 13-20, 2010.

[10] KINA, A.Y., SOUZA, V.M., TAVARES, S.S.M., et al. "Influence of heat treatments on the intergranular corrosion resistance of the AISI 347 cast and weld metal for high temperature services", Journal of Materials Processing Technology. v. 199, p. 391-395, 2008.

[11] HU, H. "Recovery, recristallization and grain-growth structures", ASM Handbook. v.9, Metallography and Microestruture, 1998. 
[12] YOON, J.H., YOON, E.P., LEE, B.S. "Correlation of chemistry, microstructure and ductile fracture behaviours of niobium-stabilized austenitic stainless steel at elevated temperature”, Scripta Materialia. v. 57, p. 25-28, 2007.

[13] BROOKS, J.A., THOMPSON, A.W. "Microstructural development and solidification cracking susceptibility of austenitic stainless steel welds”, International Materials Reviews. v. 36, pp. 16-44, 1991.

[14] GILL, T.P.S., SHANKAR, V., PUJAR, M.G., et al. "Effect of Composition on The Transformation of $\delta$-ferrite to $\sigma$ in Type 316 Stainless Steel Weld Metals", Scripta Metallurgica et Materialia. v. 32, n. 10, pp. 595-1600, 1995.

[15] PASSOS, D.O., OTUBO, J. “A influência da ferrita delta em aços inoxidáveis austeníticos forjados”, Revista Escola de Minas., v. 63, n. 1, pp. 57-63, 2010.

[16] DAVID, S.A., VITEK, J.M., ALEXANDER, D.J. "Embrittlement of Austenitic Stainless Steel Welds", Journal of Nondestructive Evaluation. v. 15, pp. 3-4, 1996.

[17] TERRA, R.F. "Estudo da influência dos tratamentos térmicos de solubilização e estabilização em junta soldada de aço inoxidável austenítico 347 (AISI 347)", Projeto Final de Graduação, LAMAV / Universidade Estadual do Norte Fluminense-UENF, Campos dos Goytacazes, RJ, Brasil, 85p., 2013.

[18] PESSANHA, E.C. “Quantificação da ferrita $\delta$ e a avaliação da relação microestrutura/propriedades de um aço inoxidável austenítico 347 soldado", Dissertação de M.Sc., LAMAV/Universidade Estadual do Norte Fluminense-UENF, Campos dos Goytacazes, RJ, Brasil, 95p., 2011.

[19] VACH, M., KUNÍKOVÁ T., DOMÁNKOVÁ M., et al., "Evolution of secondary phases in austenitic stainless steels during longterm exposures at 600,650 and $800^{\circ} \mathrm{C}$ ", Materials Characterization. v. 59, pp. 1792-1798, 2008. 